\title{
Future strategies for improving ruminant production in Eastern Africa
}

\author{
J. J. Otim \\ Department of Animal Production, University of Nairobi, PO Box 29053, Nairobi, Kenya.
}

In Eastern Africa ruminant livestock play a major rôle in the production of milk, meat, wool, hides and skins. Cattle, camels and donkeys also provide draught power, biogas and organic fertilizer. However, due to historical legacy the potential of both indigenous and exotic ruminants still remains largely untapped, especially on small farms.

Isolated animal health and water development programmes which overlooked the importance of nutrition and management on small farms have contributed to rapid overgrazing and overstocking around waterplaces because of a dramatic increase in animal population and reallocation of essential dry season grazing reserves for national parks. The longterm effects have been the destruction of vegetation and a decline in animal production.

It is only recently that policymakers and scientists realized that the best way to achieve an increase in production from ruminants is to adopt an integrated approach which allows an optimal interplay of six interrelated factors: (a) human ecology, (b) animal health, (c) nutrition, (d) management, (e) breeding and (f) marketing.

But even with this realization research activities, project planning and implementation as well as extension services still leave much to be desired. Rural participation in the design and implementation of onfarm research and development projects is currently minimal and as a consequence the co-operation of farmers is lacking and the rate of adoption of new technologies is low.

The way ahead to increasing ruminant animal production in Eastern Africa, therefore, will require the following undertakings.

(a) A clear national policy framework that will reduce or eliminate unnecessary bureaucratic delays and that will strengthen research and extension services. In the case of the pastoral people a land tenure system that gives tribal leasehold land title a legal framework appears indispensable for progress. (b) Food supply stabilization through conservation, introduction of forage species and/or multipurpose trees and shrubs must be encouraged to overcome seasonal fluctuation in food quality and quantity.

(c) Reduction of mortality rates through better feeding, animal health programmes and management is vital.

(d) Better understanding of human ecology as a prerequisite for on-farm research and launching of development projects is a must.

(e) Characterization of indigenous stock with a view to exploitation of promising genotypes before the introduction of exotic blood through crossbreeding for further increase in productivity.

(f) Research findings which are currently lying in national archives, international journals and institutional data banks should be documented by each national government and relevant publications made available in simple form to livestock farmers. Besides saving money, this undertaking will reduce duplication of research.

(g) In addition to the present International Livestock Centre for Africa research thrusts (meat and milk, small ruminants, draught power, African food resources, etc.) it is suggested that research projects and scientists be grouped according to ecological zones so that scientists working in similar ecological zones can collaborate and exchange relevant information. This will reduce duplication and improve the efficiency of generating research results.

(h) From an economic point of view, sustainable ruminant production in the fragile tropical environment can only be achieved if optimal rather than maximal productivity is emphasized.

(i) In arid and semi-arid ecozones drought management and vegetation improvement should 
be based on extensive establishment of rainwater harvesting systems besides borehole provision. It will also improve livestock distribution and nutrition.

(j) Veterinary services need to be restructured to improve their efficiency. This will require the introduction of privatization in most aspects of veterinary services, leaving governments with the responsibility of control campaigns for major diseases. The goal should be to provide costeffective veterinary services.

(k) Breeding and crossbreeding for the provision of seed stock should be organized on a co-operative and a private basis so that government institutions remain with the responsibility of organizing artificial insemination services. Matching breed and crossbred genetic potential with their environments should be the ultimate goal of selection.

(l) North-south staff exchange is essential to enable staff to become familiar with local conditions. M.Sc. and Ph.D. students from developing countries who register with universities in the north should carry out their experiments in their own countries to give them experience in solving local problems using available equipment and interacting with the farmers they will serve. 